\title{
Interpreting Bioaccumulation Data with the Environmental Residue-Effects Database
}

PURPOSE: The purpose of this technical note is to provide information regarding the use of the Environmental Residue-Effects Database (ERED) to interpret bioaccumulation data collected during environmental assessments of dredged material or contaminated sediments.

INTRODUCTION: Evaluating the environmental consequences of contaminant bioaccumulation is a complex technical and regulatory problem (Bridges and others 1996). In part, this complexity results from the fact that bioaccumulation is a measurable phenomenon, rather than an effect. Merely identifying the presence of a chemical substance in the tissues of an organism, for example, following a bioaccumulation test, is not sufficient information to conclude that the chemical will produce an adverse effect. All chemical substances have the potential to produce adverse effects (i.e., toxicity). The discipline of toxicology is based on the observation that "the dose makes the poison." The likelihood that a chemical substance in the tissues of an organism will produce an adverse effect is a function of the physical and chemical properties of the substance, the concentration of the chemical in the tissues of the organism, and the length of time the organism is exposed to the compound. Because environmental contaminants vary so widely in their potential to produce toxicity, contaminant-specific information must be used to reach a determination regarding the potential for a bioaccumulated substance to produce adverse effects.

INTERPRETING BIOACCUMULATION DATA IN THE U.S. DREDGING PROGRAM: The U.S. Army Corps of Engineers has used bioaccumulation data to make regulatory decisions regarding the management of dredged material for over 20 years (USACE 1976). Early in the program it was decided by the Corps and the U.S. Environmental Protection Agency (EPA) that regulatory decisions regarding what level of bioaccumulation is or is not acceptable must be based on data that link a given concentration of substance " $X$ " with measurable biological effects (e.g., reduced survival, growth, or reproduction). This requirement is reflected in Section 2.3.3 of the Ocean Testing Manual (USEPA/USACE 1991), which states that

"To use bioaccumulation in a decision, it is necessary to predict whether there will be a cause-andeffect relationship between the animal's presence in dredged material and a meaningful adverse elevation of body burden...."

Bioaccumulation data are evaluated at three levels of interpretation according to current dredged material evaluation guidance. At the first level, the amount of bioaccumulation of a specific contaminant in organisms exposed to dredged material is compared to a numerical effect limit, such as a Food and Drug Administration (FDA) action level or a fish advisory. If the concentration of a contaminant in an organism exposed to dredged material exceeds such a numerical limit, there is the potential for the dredged material disposal to have an "unacceptable adverse effect." If it does not exceed a numerical limit, or there is no published numerical limit for the contaminant(s) of concern, a second level of evaluation is undertaken, which involves a statistical comparison to data collected 
from animals exposed to a reference sediment. If bioaccumulation in the animals exposed to the dredged material is statistically greater than that of animals exposed to the reference sediment, then a third level of interpretation is initiated in which a number of evaluatory factors are considered to determine whether or not dredged material disposal will result in an "unacceptable adverse effect." According to USEPA/USACE $(1991,1998)$ guidance, the factors to be considered include:

a. Number of species tested and their phylogenetic diversity.

b. Number of bioaccumulated contaminants.

c. Magnitude of bioaccumulation.

d. Toxicological importance of contaminants.

e. Propensity for contaminants to biomagnify.

f. Comparison to background concentrations.

The utility of current bioaccumulation interpretive guidance is constrained by three important limitations: (a) the small number of published numerical limits (e.g., about nine FDA action levels) available for use in the first level of interpretation compared to the large number of contaminants commonly present in freshwater and marine sediments, (b) the uncertainties involved in applying an arbitrary statistical cutoff (i.e., $\alpha=0.05$ ), and (c) the largely qualitative/subjective nature of the evaluation factors applied in the third level of interpretation.

A BETTER WAY: One obvious approach to this dilemma is to interpret bioaccumulation data using published empirical data where tissue contaminant concentrations and resulting effects have been measured in the same organism (i.e., residue-effects data). A more direct and objective means of evaluating the potential consequences of bioaccumulation is to compare measured tissue concentrations from bioaccumulation tests to published information that describes the relationship between contaminant tissue concentrations and the likelihood for adverse effects (see McCarty (1996)) (Figure 1). Until recently, practical reliance on residue-effects information was hampered by the paucity of published residue-effects data and the rather "scattered" distribution of this information in the literature. Before residue-effects information could be put to use in a regulatory program, an accessible, centralized repository for this type of data would be needed.

In recognition of this fact, the U.S. Army Corps of Engineers, with support from the EPA, has developed the ERED. Users can query the database on-line by specifying a number of potential criteria (e.g., species, contaminant, etc.). Query results provide summaries of relevant studies along with full citations for the original studies. Results can be printed or downloaded electronically as spreadsheet files. Currently, the ERED contains data collected from 320 studies published between 1964 and 1998. From these studies, 3,014 distinct observations have been included on-line. The ERED includes data on 239 contaminants, 166 aquatic species, and 13 effect classes (e.g., survival, growth, reproduction, enzyme inhibition, etc.). Papers involving mixtures of contaminants were excluded from the database because effects could not be linked to a specific contaminant. The central 


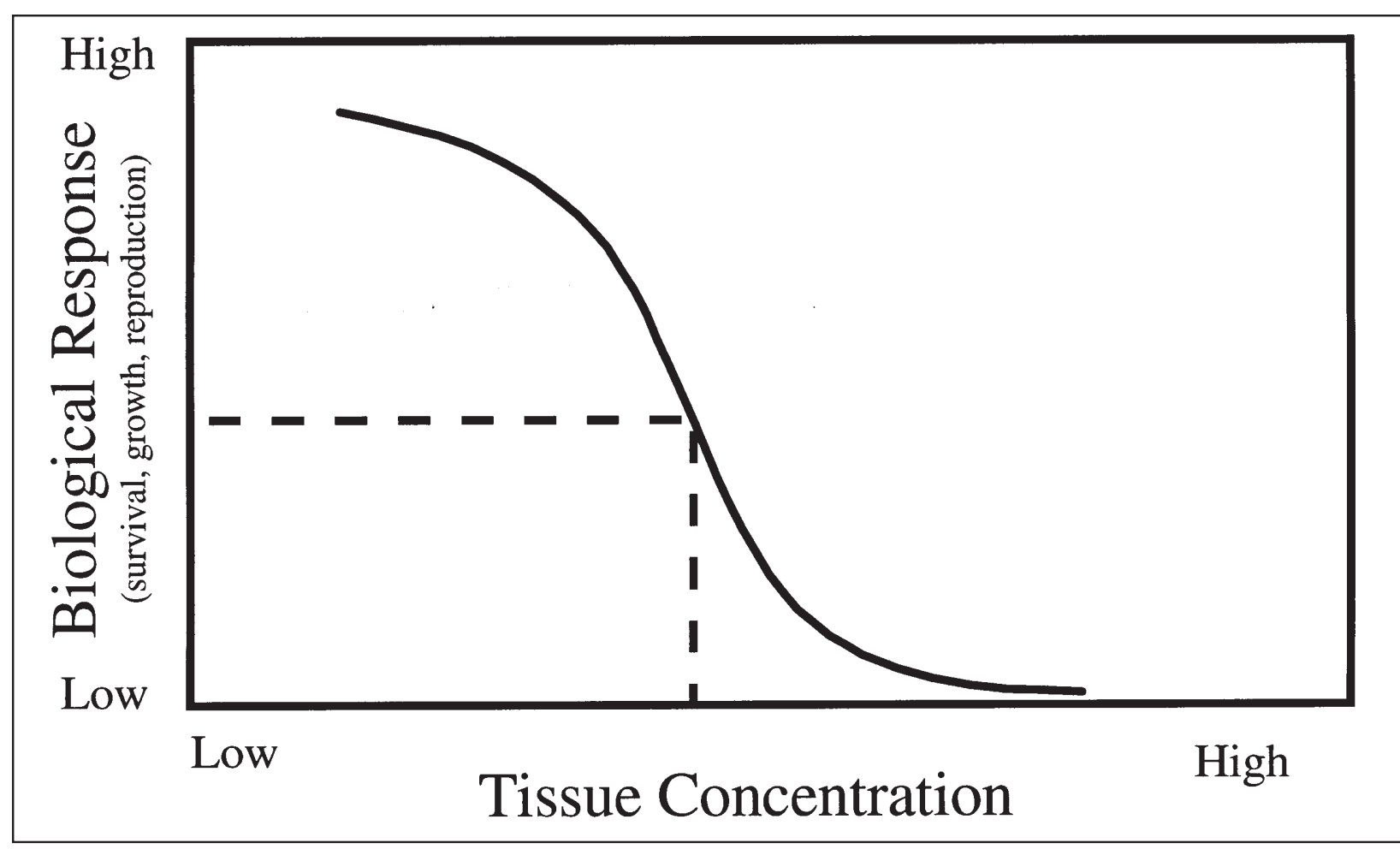

Figure 1. Dose-response relationship illustrated using contaminant tissue concentration as a measure of dose

database will be updated periodically (approximately annually) as new data sources and citations are discovered.

REGULATORY USES: In addition to the guidance provided by Bridges et al. (1996a) for incorporating consideration of residue-effects data into the tiered assessment framework for dredged material, the following considerations must be taken into account when using the ERED to make regulatory decisions about dredged material management.

\section{-Is Extrapolation Necessary to Address Concerns About Potential Impacts on Higher Trophic Level Resources Near the Disposal Site?}

In those cases where concerns about bioaccumulation of contaminants from dredged material are focused on higher trophic levels, e.g., fish, extrapolation is necessary. In the majority of cases bioaccumulation testing is performed using worms and bivalves (USEPA/USACE 1991, 1998). Contaminants may be transferred from lower to higher trophic levels (e.g., worms to fish) as lower trophic level organisms are fed on by higher trophic level organisms. The amount of contaminant transferred up the food chain depends on the chemical/physical attributes of the contaminant, the length of the food chain, the potential spatial extent of coverage for the dredged material under consideration, and the extent to which higher trophic level organisms make use of the disposal site for feeding (e.g., what percentage of a particular fish's diet comes from the disposal site). The approaches currently available for making such extrapolations range from application of simple trophic transfer coefficients (Suedel and others 1994) to use of computer-based mathematical models (Gobas 1993). Ongoing research in the Long-term Effects of Dredging Operations (LEDO) Program and the 
Dredging Operations Environmental Research (DOER) Program will contribute to future guidance on making extrapolations to higher trophic levels.

\section{-How Do I Use the Toxicological Effect Information in the ERED to Determine the Likelihood for a Meaningful Adverse Effect as Defined by the Regulations?}

When using the database for regulatory purposes, such as dredged material evaluations, the nature of the biological effect associated with a particular residue level must be considered. The ERED contains information on a broad range of biological effects caused by the presence of a particular contaminant in the tissue of an organism, from the induction of particular enzymes or enzyme systems to whole-organism effects on survival, growth, or reproduction. Cellular/sub-cellular responses are generally invoked at lower contaminant concentrations than would produce a whole-organism-level response. For this reason, contaminant levels associated with the absence (e.g., No Observed Effect Concentration) of an effect at the cellular/sub-cellular level are unlikely to produce whole-organism effects on survival, growth, or reproduction. However, the opposite is not true; that is, contaminant levels producing an effect at the cellular level will not certainly produce an effect at the level of the whole organism. In most cases, the exact nature of the relationship between the induction of a particular cellular response and the likelihood for higher order effects on whole-organism survival, growth, and reproduction is unknown. For this reason it is difficult to infer the likelihood for higher order effects on whole organisms, populations, or communities (i.e., effects the Marine Protection, Research and Sanctuaries Act and the Clean Water Act specifically state should be avoided) when cellular/sub-cellular responses alone are observed.

\section{-Are There Multiple Contaminants of Concern Present at Elevated Concentrations in the Tis- sues of Animals Exposed to Dredged Material (Compared to Reference Exposed Animals)?}

Toxicity in an organism exposed to multiple contaminants results from the cumulative influence of each contaminant present in its tissues. In simple cases where a single contaminant is present in tissue at concentrations much greater than or less than an ecologically relevant effect concentration (as found in the ERED), determining the potential for adverse effects is relatively simple. However, in those cases when multiple contaminants are present at concentrations less than but close to (e.g., within 25 percent) ecologically relevant effects concentrations, making decisions regarding the potential for adverse effects is more difficult because of the potential for cumulative effects. In such cases sound technical judgement must be exercised in reaching regulatory decisions. Summing the Hazard Quotients (tissue concentration/effect concentration, from ERED) for each of the chemicals of concern which produces adverse effects through similar biochemical/physiological mechanisms (i.e., modes of action) can help in reaching determinations about cumulative effects. This approach reasonably assumes that toxicity is generally produced in an additive manner for compounds acting by the same mode of action.

Another useful method for evaluating cumulative effects caused by multiple contaminants is the Critical Body Residue approach. As with the Hazard Quotient approach, chemicals are grouped according to their mode of action. For example, the potential for a toxic response caused by neutral organic compounds (e.g., PAHs) acting via the same mode of action (narcosis) can be estimated by summing (because of additivity) the molar concentration of all such compounds in the tissues of the organism (see McCarty and others (1992) and McCarty and Mackay (1993)). Concentration is 
expressed in terms of molar units because invoking a toxic response is dependent on the number of molecules present (e.g., mol/g wet weight tissue) rather than the contaminant's mass (e.g., parts per million, ppm). Acute narcotic effects have been generally observed at neutral organic tissue concentrations between 2 and $8 \mu \mathrm{mol} / \mathrm{g}$ wet weight (McCarty et al. 1992).

\section{-How Similar are the Bioaccumulation Test Species/Resources of Concern and the Species in the ERED?}

The uncertainty associated with applying a given effect concentration (from the ERED) to a specific bioaccumulation data set increases as the similarity decreases between the species of concern for a given project/site and the species referenced in the ERED. Ideally, one would want to use effect information on the same species that one is trying to protect at a given dredged material disposal site. In those cases where such species-specific information does not exist, care should be taken to select ecologically relevant effect values from the ERED for species that are taxonomically and ecologically similar to the species of concern at the dredged material disposal site.

\section{-Are the Experimental Conditions Used to Derive the Effect Value Appropriate for the In- tended Application?}

To increase certainty regarding the appropriateness of a particular effect value listed in the ERED, users are strongly encouraged to read and evaluate the original study from which the effect value was derived. Such an exercise will be critical in those cases where the effect value in the ERED is very close to the measured tissue concentration in the dredged material exposed animal and in those cases when making the wrong decision is costly. For example, The ERED contains effects values for animals that were exposed to specific contaminants via direct injection of the contaminants into the organism's tissues. In such cases users might choose to give greater weight to effects data collected using a more ecologically relevant route of exposure (e.g., ingestion).

Using the ERED: The ERED resides on a web server at the U.S. Army Engineer Waterways Experiment Station and is accessed via the Dredging Operations Technical Support (DOTS) home page (http://www.wes.army.mil/el/dots). Clicking on the Environmental Residue-Effects Database link loads the ERED home page (Figure 2), which contains links to various information pages concerning the ERED, including user directions. First-time users are strongly encouraged to read these directions before using the database.

Before using the ERED for the first time, each user must download and install a free plug-in for Netscape Navigator ${ }^{\mathrm{TM}}$ or Internet Explorer ${ }^{\mathrm{TM}}$. These plug-ins, along with complete installation instructions, are available on the home page. After the plug-in is installed, clicking on the "Search the ERED" link will connect the user to the ERED server, providing access to the database. ERED is designed to be presented at a screen resolution of 800x600 pixels. If a monitor is set to $640 \times 480$ pixels, the program will still work correctly, but will require scrolling to view the entire screen.

After clicking the START button on the opening ERED screen (Figure 3), the user is taken to the main query screen (Figure 4). A query is constructed using drop-down list boxes (Figure 5) and selecting up to six parameters per query. After selecting the parameters, the QUERY DATABASE button is clicked and the results are presented at the bottom of the screen. Once the data have been 
Dredging Research Technical Note EEDP-04-30

January 1999

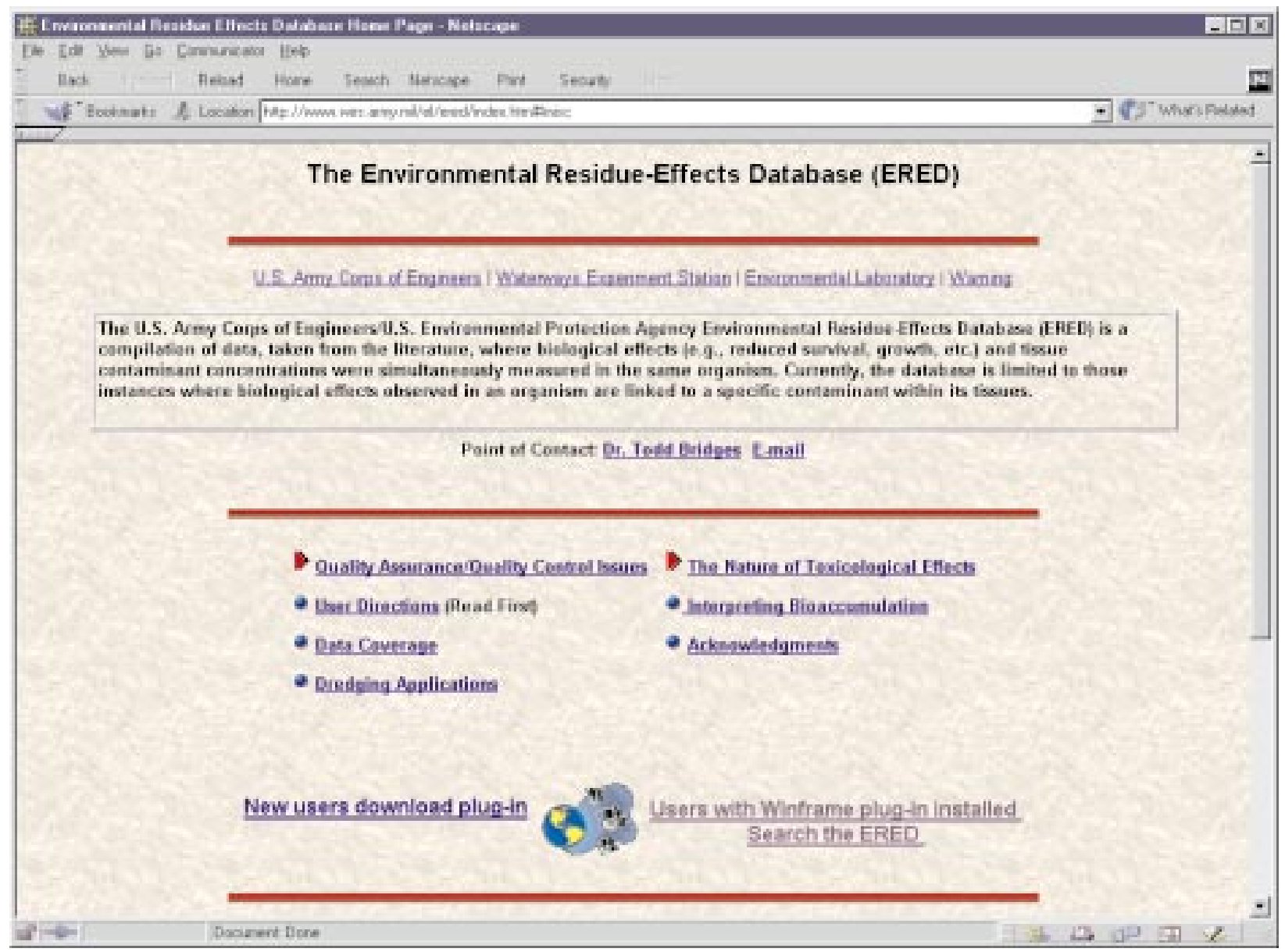

Figure 2. The ERED home page

selected from the database, the user may view the complete data, graph it (Figure 6), or download a copy of the data to a PC in spreadsheet format. Clicking the RESET ALL button clears all previous parameter selections in preparation for creating a new query. 


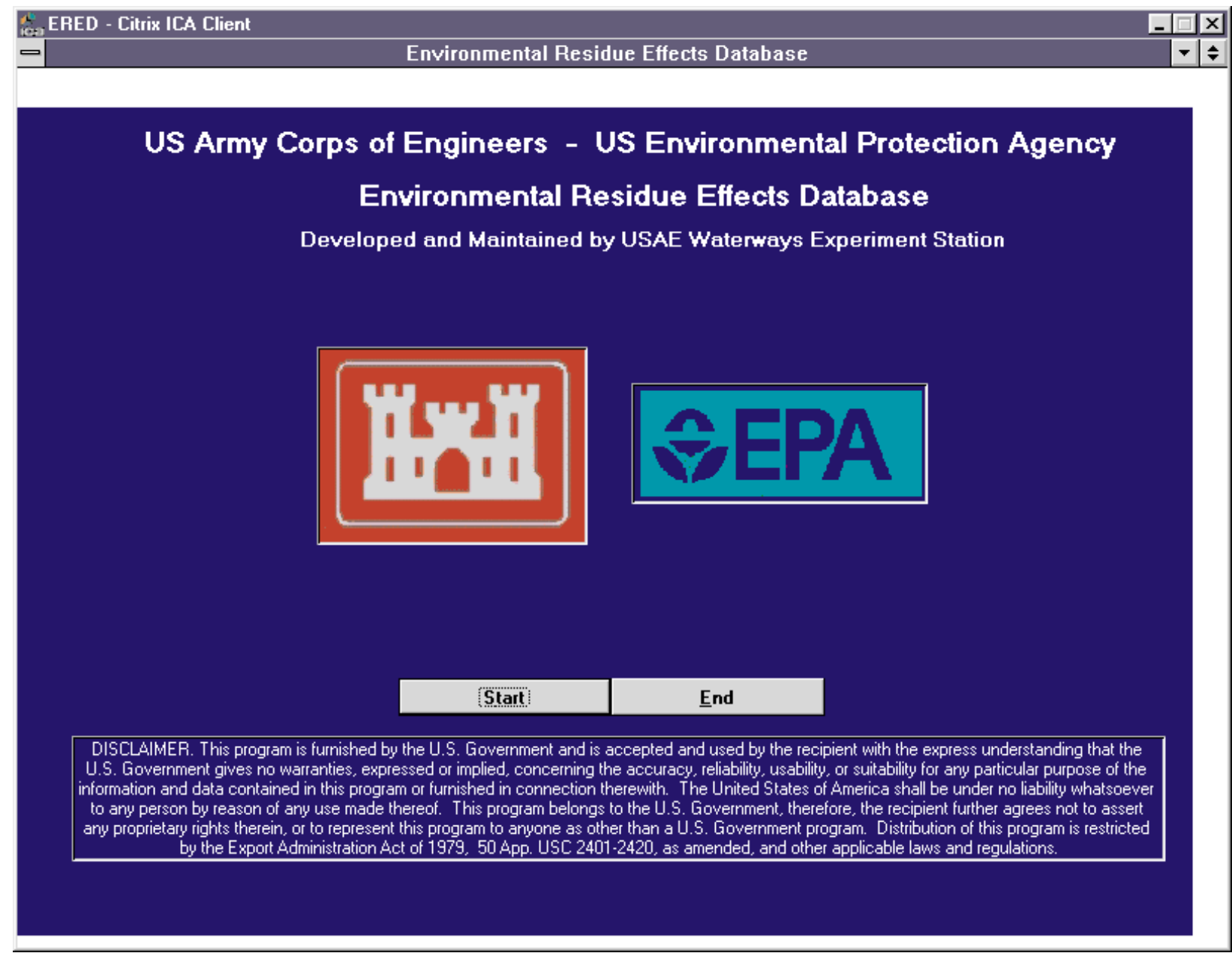

Figure 3. The opening screen of the ERED. Click the Start button to continue 
Dredging Research Technical Note EEDP-04-30

January 1999

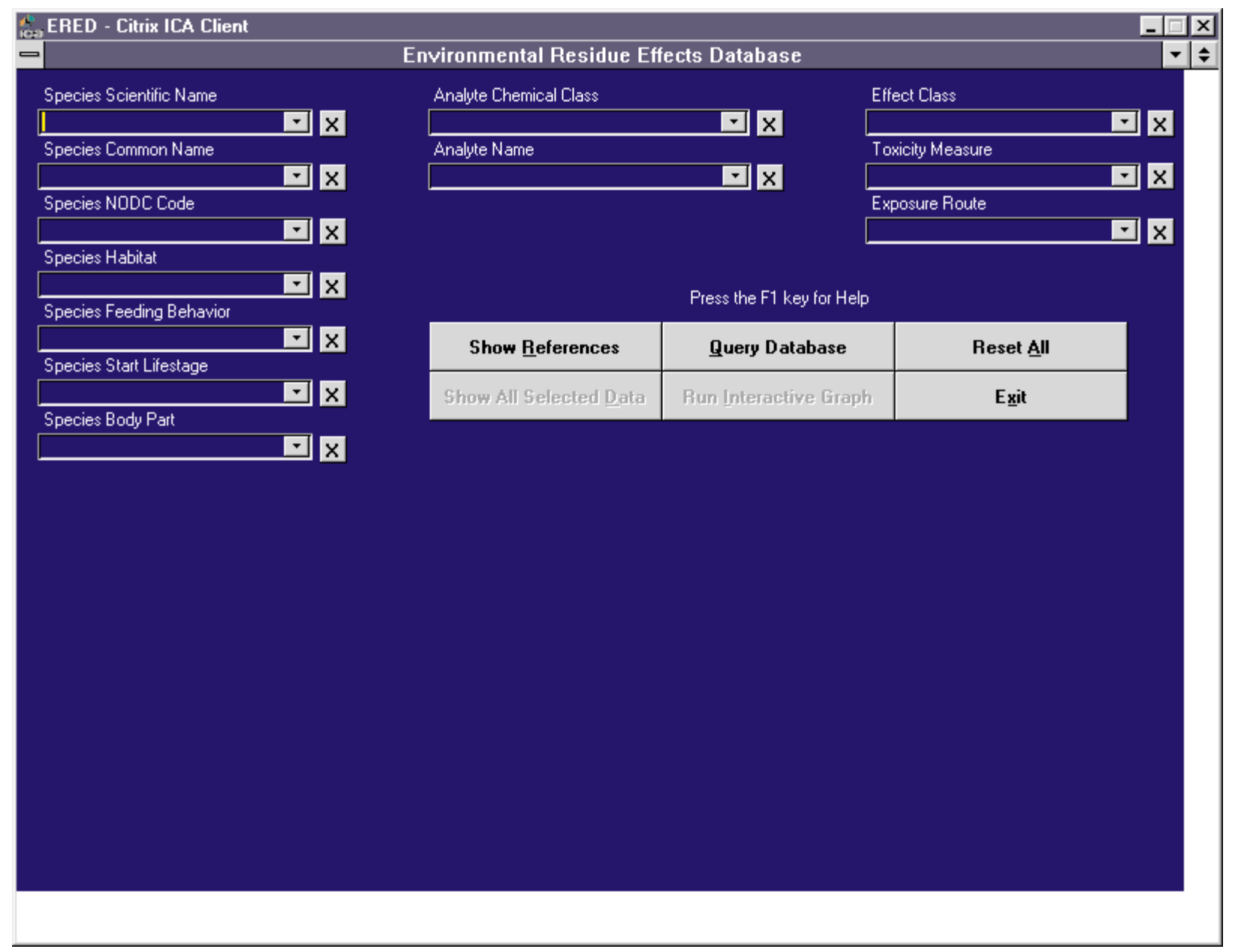

Figure 4. The main query screen. Select query options and click the "Query Database" button 


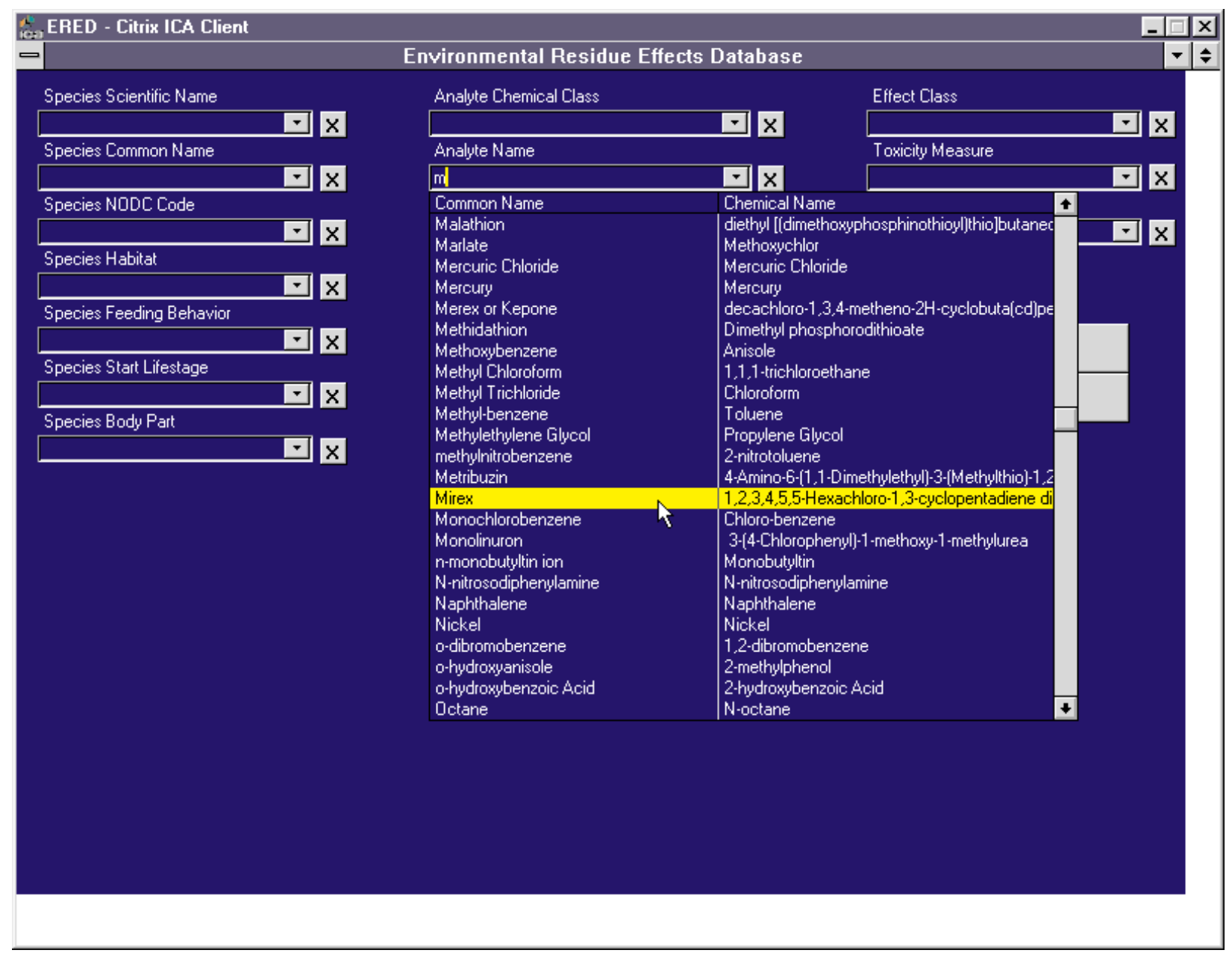

Figure 5. Example of a drop-down list used to select query options 
Dredging Research Technical Note EEDP-04-30

January 1999

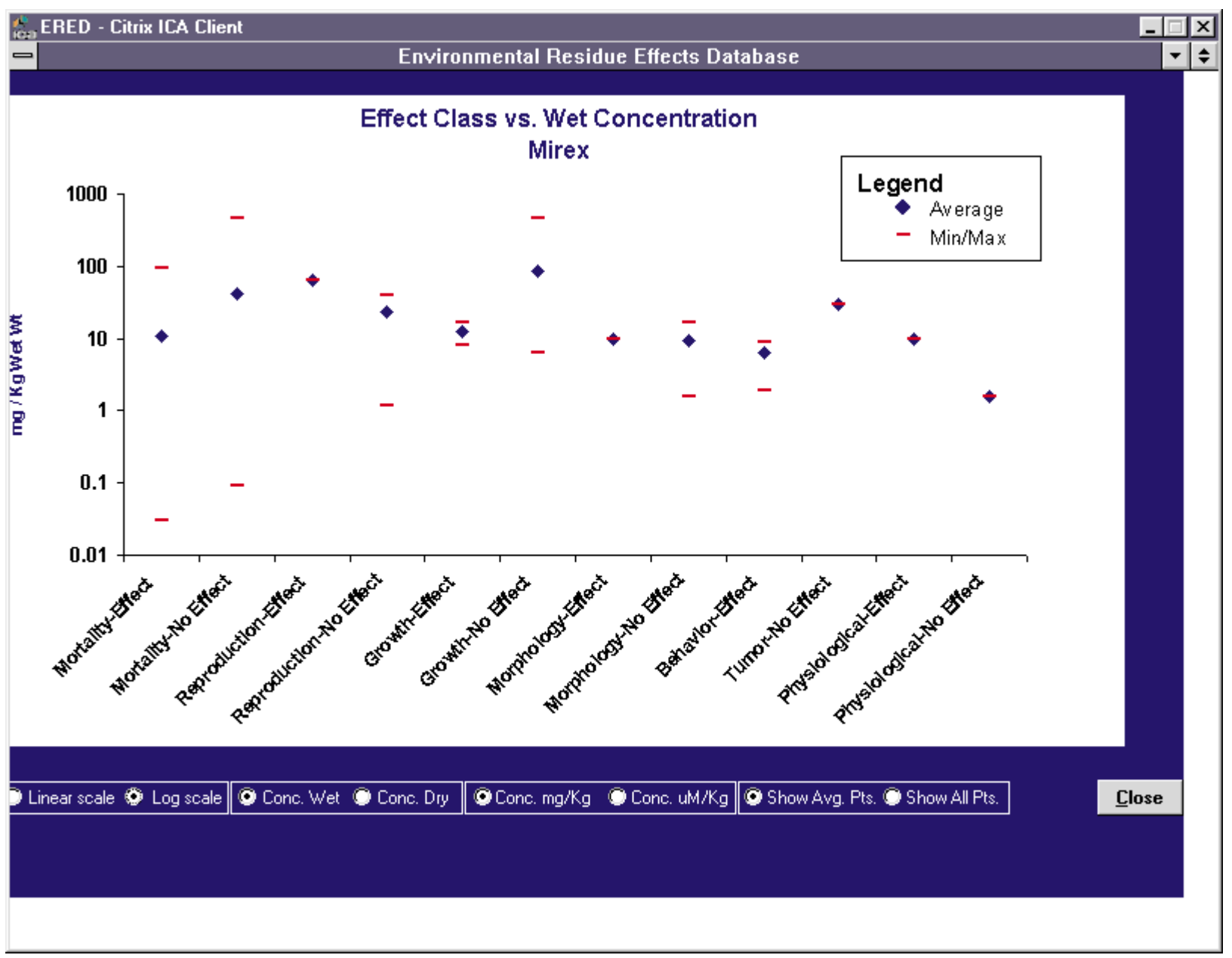

Figure 6. Example of graph created from mirex data showing thresholds of various toxicity measures

Conclusions: Although it was developed to interpret bioaccumulation data for the management of dredged materials, the ERED will be useful to ecotoxicologists, risk assessors, and others needing access to data that link measured tissue concentrations of contaminants to biological responses. In combination with risk-based approaches for estimating contaminant trophic transfer, the ERED is expected to provide a solid basis for making more objective determinations about the potential for "unacceptable adverse effects" resulting from contaminant bioaccumulation.

POINTS OF CONTACT: For additional information, contact one of the authors, Dr. Todd S. Bridges, 601-634-3626, bridget@mail.wes.army.mil, Mr. Charles H. Lutz, 601-634-2489, lutzc@mail.wes.army.mil or the manager of the Dredging Operations Technical Support (DOTS) Program, Mr. Thomas R. Patin, 601-634-3444,patint@ex1.wes.army.mil.

\section{REFERENCES}

Bridges, T. S., Moore, D. W., Landrum, P., Neff, J., and Cura, J. (1996a). "Summary of a workshop on interpreting bioaccumulation data collected during regulatory evaluation of dredged material," Miscellaneous Paper D-96-1, U.S. Army Engineer Waterways Experiment Station, Vicksburg, MS. 
Bridges, T. S., Moore, D. W., McFarland, V., Wright, T. D., Wilson, J. R., and Engler, R. M. (1996b). "Proposed new guidance for interpreting the consequences of bioaccumulation from dredged material." Technical Notes Collection (TN EEDP-01-41). U.S. Army Engineer Research and Development Center, Vicksburg, MS. www.wes.army.mil/el/dots/eedptn.

Gobas, F. (1993). "A model for predicting the bioaccumulation of hydrophobic organic chemicals in aquatic food webs: Application to Lake Ontario," Ecological Modeling 69, 1-17.

McCarty, L. S. (1996). Learned Discourse: "Comments on the significance and use of tissue residues in sediment toxicology and risk assessment," SETAC NEWS 16(6), 12-14.

McCarty, L. S., and Mackay, D. (1993). "Enhancing ecotoxicological modeling and assessment: Body residues and modes of toxic action," Environmental Science and Technology 27, 1719--1728.

McCarty, L. S., Mackay, D., Smith, A. D., Ozburn, G. W., and Dixon, D. G. (1992). “Residue--based interpretation of toxicity and bioconcentration QSARs from aquatic bioassays: Neutral narcotic organics," Environmental Toxicology and Chemistry 11, 917-930.

Suedel, B. C., Boraczek, J. A., Peddicord, R. K., Clifford,P. A., and Dillon, T. M. (1994). "Trophic transfer and biomagnification potential of contaminants in aquatic ecosystems," Reviews of Environmental Contamination and Toxicology 136, 21-89.

U.S. Army Corps of Engineers. (1976). "Ecological evaluation of proposed discharge of dredged or fill material into navigable waters," Miscellaneous Paper D-76-17, U.S. Army Engineer Waterways Experiment Station, Vicksburg, MS.

U.S. Environmental Protection Agency/U.S. Army Corps of Engineers. (1991) "Evaluation of dredged material proposed for ocean disposal - testing manual," EPA-503/8-91/001, USEPA Office of Water, Washington, DC.

U.S. Environmental Protection Agency/ U.S. Army Corps of Engineers. (1998). "Evaluation of dredged material proposed for discharge in waters of the U.S.-testing manual," EPA 823-F-94-002, USEPA Office of Water, Washington, DC. 